\title{
Reconsolidation and the Dynamic Nature of Memory
}

\author{
Karim Nader \\ Psychology Department, McGill University, Montréal, Quebec H3A 1B1, Canada \\ Correspondence: karim.nader@mcgill.ca
}

\begin{abstract}
Memory reconsolidation is the process in which reactivated long-term memory (LTM) becomes transiently sensitive to amnesic agents that are effective at consolidation. The phenomenon was first described more than 50 years ago but did not fit the dominant paradigm that posited that consolidation takes place only once per LTM item. Research on reconsolidation was revitalized only more than a decade ago with the demonstration of reconsolidation in a well-defined behavioral protocol (auditory fear conditioning in the rat) subserved by an identified brain circuit (basolateral amygdala). Since then, reconsolidation has been shown in many studies over a range of species, tasks, and amnesic agents, and cellular and molecular correlates of reconsolidation have also been identified. In this review, I will first define the evidence on which reconsolidation is based, and proceed to discuss some of the conceptual issues facing the field in determining when reconsolidation does and does not occur. Last, I will refer to the potential clinical implications of reconsolidation.
\end{abstract}

earning and memory are commonly depictLed as going through a set of phases. There is the learning or encoding phase, in which information is acquired, by stabilization phase, in which specific mechanisms are engaged to stabilize initially unstable new information (referred to as synaptic consolidation) (Glickman 1961; McGaugh 1966), the "storage" or maintenance phase, during which other mechanisms are involved to maintain the memory, and the retrieval phase, in which specific mechanisms permit a memory to be retrieved (Miller and Springer 1973; Spear 1973). For a long time, from a neurobiological perspective, only acquisition and memory stabilization (Martin et al. 2000; Kandel 2001; Dudai 2004) were considered to be active phases, in the sense that neurons had to perform certain computations or synthesize new RNA and proteins for these phases of memory processing to be performed successfully. After acquisition and stabilization, all other phases were implicitly thought by many to be passive readout of changes in the circuits mediating the long-term memory (LTM). However, the picture has now changed and the maintenance of memory is portrayed as an active process. One of the reasons for this change is the demonstration that a consolidated LTM can become susceptible to disruption and restoration, a process termed "reconsolidation" (Spear 1973; Nader et al. 2000; Sara 2000). There are now detailed molecular and cellular models of this time-dependent active memory phase.

This review will first describe the logic of the findings that brought the existence of the consolidation process to light. I will then describe how we concluded that a consolidated memory undergoes reconsolidation in a well-defined be-

Editors: Eric R. Kandel, Yadin Dudai, and Mark R. Mayford

Additional Perspectives on Learning and Memory available at www.cshperspectives.org

Copyright (C) 2015 Cold Spring Harbor Laboratory Press; all rights reserved; doi: 10.1101/cshperspect.a021782

Cite this article as Cold Spring Harb Perspect Biol 2015;7:a021782 


\section{K. Nader}

havioral protocol (auditory fear conditioning in the rat). I will then refer to the range of species, tasks, and treatments in which reconsolidation have been reported. One aspect of reconsolidation that has attracted experimental attention involves the finding that there seem to be conditions that facilitate, inhibit, or even prevent reconsolidation from occurring. I present an approach that could help to identify such conditions. Last, I will discuss potential clinical implications of reconsolidation.

\section{CONSOLIDATION: THE DOMINANT MODEL OF MEMORY STORAGE}

Consolidation is the time-dependent stabilization of newly acquired memory (Fig. 1Ai) (Ebbinghaus 1885; Müller and Pilzecker 1900; Glickman 1961; McGaugh 1966, Dudai 2004). At the synaptic level of analysis, this process, referred to as synaptic consolidation, is thought to be a universal property of neurons that subserve memory formation.

The evidence for the consolidation process has been derived from various lines of evidence demonstrating the presence of a postacquisition time interval during which new memories are labile and sensitive to challenges (Fig. 1Ai). First, performance can be impaired by amnesic treatments, such as electroconvulsive shock (Duncan 1949), protein synthesis inhibitors (PSIs) (Flexner et al. 1965), or by new learning (Gordon and Spear 1973). Second, retention can be enhanced by administration of certain compounds, such as strychnine (McGaugh and Krivanek 1970). Crucially, these manipulations are only effective when administered shortly after new learning, but not when given after a few hours. These types of results led to the conclusion that memory exists in two states. When susceptible to enhancement or impairment, memory resides in a labile state, but if it is insensitive to these treatments, memory is stable and, by definition, consolidated (McGaugh 1966; Dudai 2004).

This same logic was used by Schafe and colleagues to test for the existence of a consolidation process in the lateral and basal amygdala (LBA) for auditory fear memory. When an amnesic agent, the protein-synthesis inhibitor anisomycin, is infused into the LBA, shortly after training, short-term memory (STM) is intact but LTM is impaired (Fig. 1Aii) (Schafe and LeDoux 2000); however, LTM remains intact when the infusion is delayed for $6 \mathrm{~h}$. This pattern of results conforms to the operational definition of consolidation in the sense that the aspect of fearconditioning memory that requires protein synthesis within the LBA is consolidated within at most $6 \mathrm{~h}$ after learning. In addition, we assume that the experimental manipulation-induced amnesia for those computations that the LBA supposedly mediates, that is, the association between the conditioned stimulus (the tone; CS) and the unconditioned stimulus (the foot shock; US) (Rodrigues et al. 2009).

One of the tenets of the cellular consolidation model is that learning induces changes in synaptic efficacy, suggesting that the physiological "unit" of cellular consolidation is the synapse. Two main candidate cellular mechanisms that were postulated to implement these changes are long-term potentiation (LTP) and longterm depression (LTD) (Malenka and Nicoll 1999; Martin et al. 2000). In parallel to the distinction of STM and LTM, with the latter being consolidated by a protein-synthesis-dependent process, LTP is also divided into an early transient phase (E-LTP) and a stabilized, RNA- and protein-synthesis-dependent late phase (L-LTP) (Goelet et al. 1986).

\section{BEHAVIORAL EVIDENCE FOR A RECONSOLIDATION PROCESS}

The existence of a reconsolidation process in the LBA for consolidated, that is, long-term auditory fear memory was identified in a study ( $\mathrm{Na}$ der et al. 2000) that in logic and design followed those for consolidation as described in Schafe and LeDoux (2000). One day after conditioning, at a time when, according to the results from the consolidation study, memory should be stabilized and immune to the amnesic agent, we reminded animals of the conditioning session by exposing them again to the CS, that is, the tone (Nader et al. 2000). Anisomycin, at the same dose, concentration, and rate as in the 
A

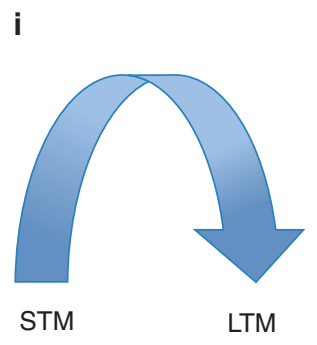

B

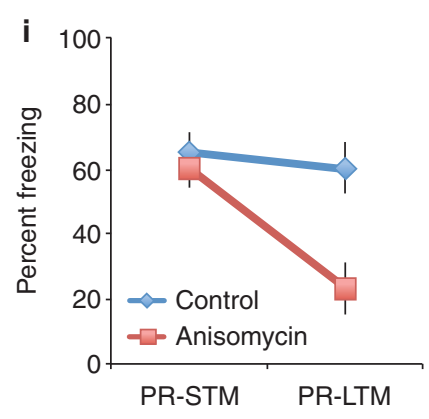

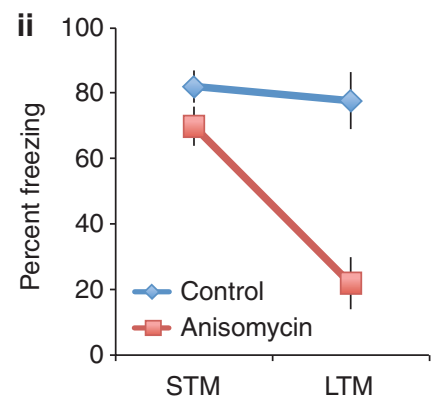

ii

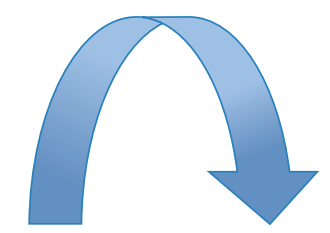

Inactive Active memory memory

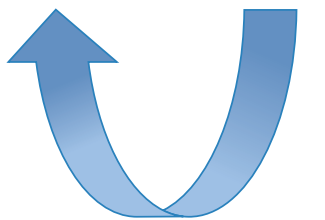

Figure 1. Conceptual model of time-dependent memory processes. (Ai) Textbook account of consolidation demonstrating that memories consolidate over time into long-term memory (LTM). The critical point is to show that once a memory is in LTM, it is thought to remain fixed or permanent (Glickman 1961; McGaugh 1966). (Aii) A typical demonstration of a consolidation blockade (Schafe and LeDoux 2000) -intact short-term memory (STM) and impaired LTM, a pattern of impairment that defines a consolidation impairment (Dudai 2004; McGaugh 2004). (Bi) A typical demonstration of a reconsolidation blockade. Intact postreactivation STM (PR-STM) and impaired LTM (PR-LTM), meeting the definitions for a consolidation blockade (Dudai 2004; McGaugh 2004). (Bii) An alternate model of memory that incorporates the findings of consolidation and reconsolidation datasets proposed by Lewis (1979). Consolidation theory cannot explain the reconsolidation dataset. New and reactivated memories are in an "active state" and then over time they stabilize and exist in an "inactive memory state." When a memory in an inactive memory state is remembered it returns to an active memory state.

consolidation study (Schafe and LeDoux 2000) was then infused into the LBA either immediately or $6 \mathrm{~h}$ after the memory retrieval. When anisomycin was administered immediately, anisomycin-treated animals show intact postreactivation STM (PR-STM) but impaired PR-LTM (Fig. 1Bi), a pattern of results that is identical to what is found when blocking consolidation (Fig. 1Aii) (Schafe and LeDoux 2000). However, if the postreactivation infusion was delayed by $6 \mathrm{~h}$, anisomycin had no effect, demonstrating that the reactivation-induced lability was transient. Importantly, animals that were not reminded before anisomycin infusions had intact memory.

Staying strictly within the commonly accepted consolidation framework, and applying only the rationale on which this framework is 
based, the following four conclusions can be drawn from the results of these experiments. First, the observation that the memory was insensitive to anisomycin when it was not reactivated shows that it was "consolidated" $24 \mathrm{~h}$ after training - at least with regard to the specific amnesic treatment applied. Second, that only the reactivated memory was sensitive to disruption shows that memory was in a labile state after reactivation. Third, the observation that the anisomycin-treated animals showed intact STM and impaired LTM after reactivation implies that a consolidation-like process is triggered by reactivation. And finally, given the amnesic treatment was ineffective $6 \mathrm{~h}$ after reactivation, this postreactivation restabilization process is, like consolidation, a time-dependent process. Taken together, these four conclusions yield the interpretation that reactivation of a consolidated memory returns it again to a labile state from which the memory has to undergo stabilization (i.e., reconsolidate) over time (Nader et al. 2000).

Consolidation and reconsolidation are, thus, both deduced from the evidence of a transient period of instability. In the case of consolidation, this window is initiated after acquisition of new information. In the case of reconsolidation, it is initiated after reactivation of an existing, consolidated memory representation. As is the case for consolidation, only during the reconsolidation phase can memory be enhanced by "memory enhancers" (Gordon 1977b; Rodriguez et al. 1993, 1999; Horne et al. 1997), or impaired by either amnesic treatments (Misanin et al. 1968) or interference produced by new learning (Gordon 1977a). These treatments are ineffective when reconsolidation is complete, which is also the case for consolidation.

The term "reconsolidation" was originally introduced in the context of a discussion on memory retrieval. Spear (1973) asked “... how will the dynamic aspects of memory be handled, that is, with successive learning trials or related successive experiences does the entire memory reconsolidate anew or merely the new information?" As a consequence of the perceived inability of the consolidation hypothesis to account for reconsolidation, new memory models were developed that treated new and reactivated consolidated memories in similar ways (Fig. 1Bii) (Spear 1973; Lewis 1979).

In recent years, reconsolidation has been shown across a variety of species, tasks, and amnesic treatments (Table 1). In light of this evidence, it was therefore postulated that reconsolidation represents a fundamental memory process (Nader and Hardt 2009). One of the most striking findings in this literature is a study by Lee (2008), who devised specific tools to block consolidation or reconsolidation mechanisms. Most students of memory would assume that presenting additional learning trials to a consolidated memory would engage consolidation mechanisms, which will make the memory stronger. However, the evidence from the aforementioned study suggests that a memory has to undergo reconsolidation to be strengthened. Moreover, memory strengthening by new learning was mediated by reconsolidation and not consolidation mechanisms. This evidence suggests that a recently acquired memory will be mediated by consolidation mechanisms within a time window of $\sim 5 \mathrm{~h}$. However, for the rest of the memory's lifetime, the memory will engage reconsolidation mechanisms (Lee 2009).

\section{ALTERNATIVE INTERPRETATIONS}

Reconsolidation, as we discussed above, has been defined by applying the very standards that define consolidation. Therefore, certain nonspecific interpretations of the reconsolidation hypothesis pose the same challenges to the consolidation hypothesis, a consequence that is rarely acknowledged. The complexity of the data poses a problem for alternative interpretations, which should not merely provide new explanations for the reconsolidation dataset, but need to allow for predictions that are different from those offered by the reconsolidation model. For this reason, we will not address all the previous alternative interpretations here. A detailed discussion of these alternative interpretations including facilitation of extinction, transient retrieval impairment, nonspecific effects, state-dependent learning, and new learning is presented in Nader and Hardt (2009). 
Reconsolidation and the Dynamic Nature of Memory

Table 1. Some of the paradigms in which reconsolidation has been reported

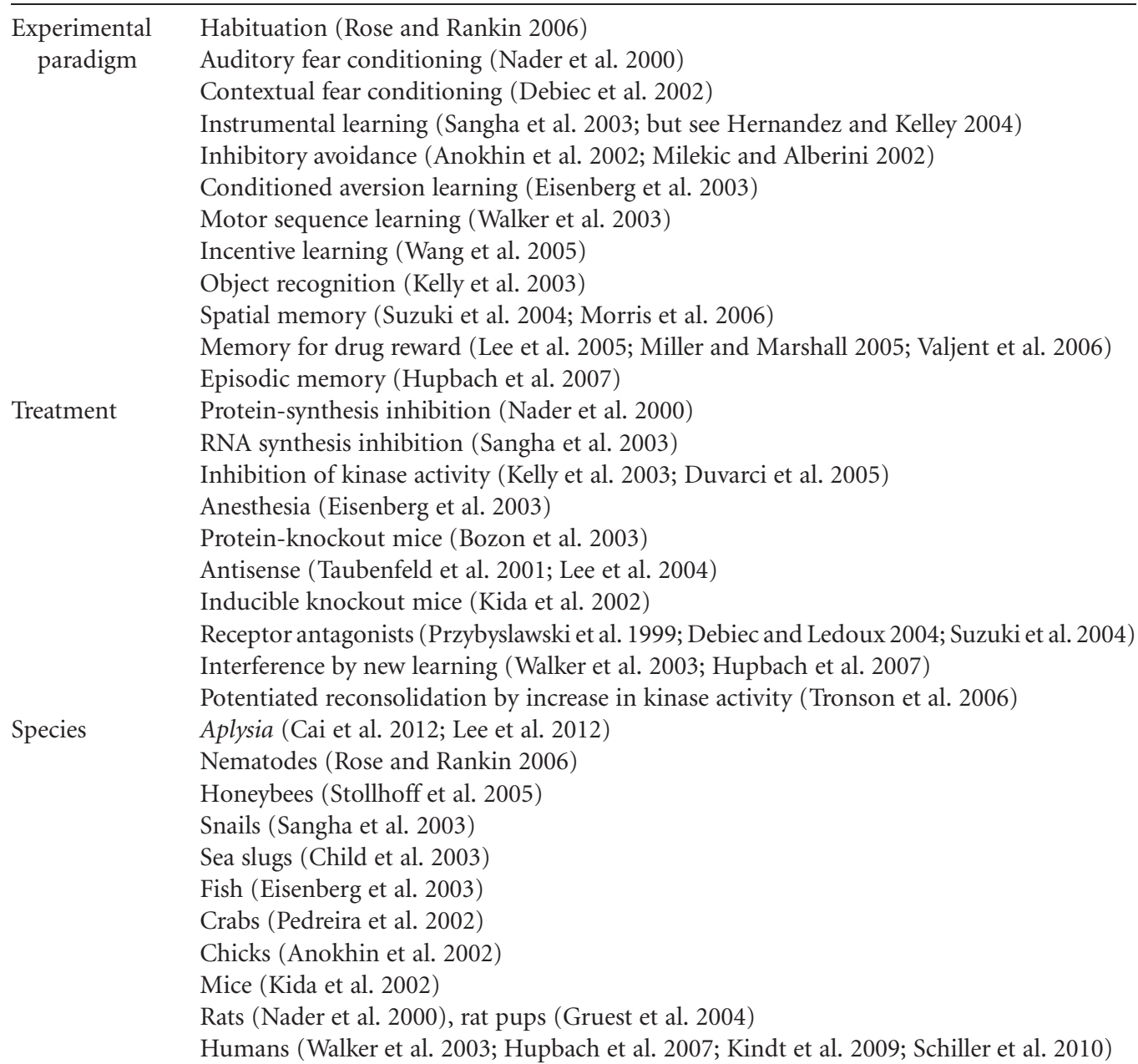

Examples from various experimental paradigms, treatments, and species for studies reporting evidence for a reconsolidation process since the year 2000.

\section{EVIDENCE FOR RECONSOLIDATION ACROSS LEVELS OF ANALYSIS}

Evidence for reconsolidation does not come solely from the behavioral level of analysis. A cellular phenomenon akin to reconsolidation was shown for L-LTP (Fonseca et al. 2006). In this study, the investigators report that when anisomycin is added $2 \mathrm{~h}$ after the induction of L-LTP, it has no effect on L-LTP maintenance. If, however, the potentiated pathway is reactivated by administering test pulses that inhibit protein synthesis, the potentiation is intact shortly after reactivation but becomes impaired over time.
This suggests that reactivation of stabilized LLTP returns its substrate to a labile state, in which it can be disrupted by inhibiting protein synthesis. Other evidence includes reports that reconsolidation blockade reverses increases in field potentials induced by fear conditioning in the lateral amygdala (LA) in intact animals (Doyere et al. 2007). In summary, this evidence suggests the presence of a cellular correlate of the behaviorally shown reconsolidation impairment.

More recently, two papers using the classic paradigm of Aplysia to study sensitization and long-term facilitation (LTF) reported that reconsolidation affects these kinds of processes. 
Indeed, when reconsolidation was blocked, the sensory-motor synaptic enhancement typically observed after LTF was reversed (Cai et al. 2012; Lee et al. 2012).

At the molecular level, interfering with reconsolidation can, in a time-dependent manner, remove molecular correlates of memory induced by learning and subsequent consolidation. Miller and Marshall (2005) showed that place-preference learning activates the extracellular signal-regulated kinase (ERK) in the nucleus accumbens. Blocking the activated ERK in the nucleus accumbens after reactivation results in intact PR-STM but impaired PRLTM. In these amnesic animals, this also leads to the absence of ERK and its downstream transcription factors in the nucleus accumbens (see also Valjent et al. 2006, who show a reduction in ERK and GluA1 phosphorylation using a similar procedure). Studying mechanisms of long-term habituation in Caenorhabditis elegans, Rose and Rankin (2006) showed that administering heat-shock or the non- $N$-methylD-aspartate (NMDA) glutamatergic antagonist, DMQX, after reactivation of a consolidated memory dramatically returns expression of $\alpha$ amino-3-hydroxy-5-methyl-4-isoxazolepropionic (AMPA) receptors in the mechanosensory neuron to a level typical for naive animals (Rose and Rankin 2006). Importantly, the reconsolidation effects in all of these studies were contingent on memory reactivation-in the absence of a reminder the amnesic treatments were ineffective.

Another study described the biochemical process that destabilizes a consolidated memory and the subsequent reconsolidation process at the level of postsynaptic AMPA receptors. Learning is thought to lead to AMPA receptor trafficking: calcium-permeable AMPA receptors are inserted into the postsynaptic density (PSD), then over time replaced by calcium-impermeable receptors (Rumpel et al. 2005). Hong et al. (2013) asked what the AMPA receptor dynamics would be when a memory is destabilized and then reconsolidated. They found that memory destabilization is associated with calcium-permeable AMPA receptors. Indeed, blocking the introduction of calcium-perme- able AMPA receptors into the PSD prevented the memory from being apparently unstored. Thus, they found that the replacement of calcium-permeable AMPA receptors by calcium-impermeable AMPA receptors mediated the process of reconsolidation.

These studies are only examples of the dataset that provides strong evidence for the existence of a transient postreactivation period of memory plasticity, that is, memory reconsolidation, on the behavioral, physiological, and molecular levels of analysis.

\section{CAN MECHANISMS MEDIATING PRESYNAPTIC PLASTICITY UNDERGO RECONSOLIDATION?}

Both post- and presynaptic mechanisms are posited to contribute to synaptic plasticity and memory (Finnie and Nader 2012; Kandel et al. 2014). One theory on the locus of memory posits that presynaptic changes are critical for LTM and L-LTP (Bliss and Collingridge 1993). These presynaptic changes are thought to increase the probability of vesicle release.

In studies that examined cellular or molecular correlates of consolidation or reconsolidation, blocking the respective memory processes were reported to reverse the learning-induced molecular/cellular correlates. For example, Bailey and Kandel (1993) reported that the blockade of consolidation in Aplysia with a proteinsynthesis inhibitor prevented the increase in the number of synapses following sensitization to the point where this number of synapses was comparable to the level of synapses in naïve animals. The same pattern of results has been shown in reconsolidation studies, as can be seen in the previous section.

Tsvetkov et al. (2002) have shown that auditory fear conditioning induces predominantly presynaptic enhancements in both inputs to the LA thought to mediate fear learning. Recently, this group assessed what would happen to these learning-induced presynaptic enhancements after blocking reconsolidation with rapamycin, a protein-synthesis inhibitor. They reported that these presynaptic enhancements were not reduced, but that a reduction in postsynaptic AMPA receptors correlated with the behavioral 
impairments ( $\mathrm{Li}$ et al. 2013). This finding suggests that the postsynaptic mechanisms detect how much potential exists on the presynaptic terminals and adjusts the postsynaptic AMPA receptors accordingly.

There are two theoretical implications of these findings for reconsolidation. First, perhaps, presynaptic mechanisms of long-term plasticity are independent of reconsolidation. This would entail that only the postsynaptic mechanisms of LTM could be susceptible to reconsolidation blockade. The second possibility is that presynaptic mechanisms are affected by reconsolidation, but the amnesic treatment used, a PSI, was not appropriate to target the presynaptic mechanisms mediating reconsolidation. We know that presynaptic enhancements are not affected by PSIs. Therefore, a tool transiently challenging the mechanisms mediating long-term presynaptic efficacy would be needed to test this hypothesis.

\section{RECONSOLIDATION IS NOT UNIVERSAL}

The fact that memory reconsolidation has been found across levels of analysis does not imply that reconsolidation is universal, that is, observed under any circumstance. Another variation of the theme that reconsolidation is not a universal property of memory is the concept of constraints on this phenomenon, or "boundary conditions." These are conditions of a physiological, environmental, or psychological nature, in which memory that normally would reconsolidate no longer does. Several boundary conditions have been proposed, such as the dominance of the association over behavior ( $\mathrm{Ei}$ senberg et al. 2003), competition with extinction (Eisenberg et al. 2003; Pedreira and Maldonado 2003; Suzuki et al. 2004), memory age (Milekic and Alberini 2002; Eisenberg and Dudai 2004; Suzuki et al. 2004), predictability of the reactivation stimulus (Pedreira et al. 2004; Morris et al. 2006), and training intensity (Suzuki et al. 2004). Others, however, have not identified similar boundary conditions in other protocols for extinction (Stollhoff et al. 2005; Duvarci et al. 2006), old memories (Debiec et al. 2002; Lee et al. 2005), predictability of the reactivation stimulus (Pedreira et al. 2002; Bozon et al 2003; Sangha et al. 2003; Valjent et al. 2006), or strength of training (Debiec et al. 2002; Lee et al. 2005). Whether additional parameters moderate boundary conditions remains to be seen.

The observed inconsistencies in the identification of the boundary conditions might be caused by the absence of agreed-on, standard experimental parameters required to test the presence of such boundary conditions. For example, if memory disruption is not observed within a set of experimental parameters, then it is concluded that the memory does not undergo reconsolidation under those conditions. A number of reports, however, have shown that a memory may undergo reconsolidation only under specific reactivation conditions (De Vietti and Holiday 1972; Bozon et al. 2003; Suzuki et al. 2004). The implication of these findings is that it is difficult to conclude, based on behavioral studies, that a memory never undergoes reconsolidation. Therefore, the question remains whether the negative effects on which the boundary conditions are based imply that a given memory never undergoes reconsolidation under those inferred conditions, or that same memory is still capable of undergoing reconsolidation with a different reactivation protocol that still includes the same inferred boundary conditions (Figs. 2 and 3). Given that the parameter space of possible reactivation procedures is essentially infinite, a generalized boundary condition may be difficult to prove at the behavioral level. This may explain part of the inconsistency in the field of boundary conditions of reconsolidation (Dreyfuss et al. 2009).

An understanding of how boundary conditions are mediated across levels of analysis is critical because targeting reconsolidation of traumatic memories has been proposed to be a potential treatment for posttraumatic stress disorder (PTSD) (Przybyslawski and Sara 1997; Debiec et al. 2002; Schiller et al. 2010). Specifically, blocking the reconsolidation of traumatic memories might weaken the long-term maintenance of these traumatic memories, in turn, reducing PTSD pathology. However, if strong aversive experiences act as boundary conditions on reconsolidation (Suzuki et al. 2004), then 
K. Nader

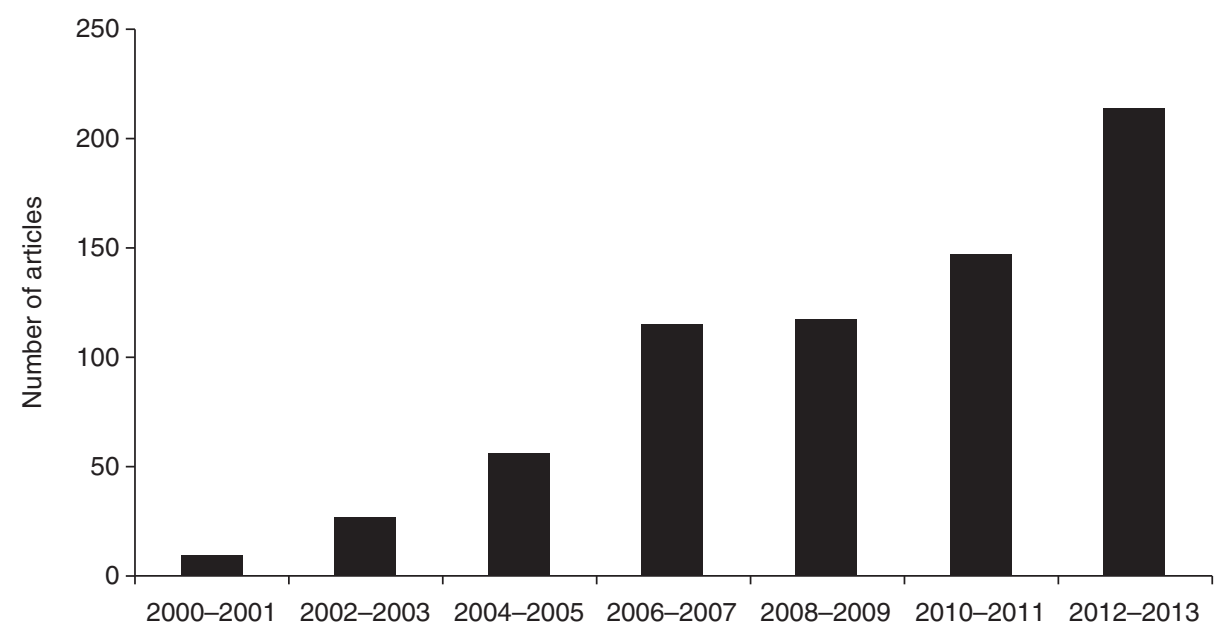

Figure 2. The number of articles published with reconsolidation in the abstract (based on data in Nader et al. 2000).

this would suggest that the traumatic memories in PTSD patients may be resistant to undergoing reconsolidation thereby negating reconsolidation as a potential therapeutic target. Therefore, understanding boundary conditions, such as strength of training, is critical to ensure we know whether it is possible to target reconsolidation of very strong fear memories and, if so, what the optimal conditions are to allow an extremely strong fear memory to undergo reconsolidation.

To this end, Wang et al. (2009) found that strong auditory training produced memories that initially did not undergo reconsolidation but they did so over time on the order of 1 mo. This suggests that the boundary condition induced by strong training is transient (Fig. $4 \mathrm{~A})$. This in itself is striking, as the implicit assumption is that once a memory stops undergoing reconsolidation it will never begin again. This was the first demonstration that a putative boundary condition could be transient (Wang et al. 2009).

Wang et al. (2009) hypothesized that one principle that could mediate boundary conditions is to down-regulate the mechanisms that allow memories to undergo reconsolidation (Fig. 5). What could the molecular mechanism be that inhibit reconsolidation of strong memories for up to $30 \mathrm{~d}$ after training in the LBA?
Ben Mamou et al. (2006) showed the NMDA receptor antagonists for the NR2B subunits are necessary in reactivation-induced destabilization, but that this destabilization does not get expressed at the behavioral level. Specifically, prereactivation administration of ifenprodil (an NR2B antagonist) prevented the memory from being impaired by postreactivation anisomycin; however, the ifenprodil itself had no effect on the expression of freezing (Fig. 6). New strong memories show similar properties: normal expression of freezing during reactivation but insensitivity to postreactivation anisomycin. The investigators reasoned that strong training may down-regulate NR2B expression in the LBA, thereby making the memory insensitive to postreactivation anisomycin infusions but capable of being expressed normally. The investigators suggest that NR2B expression in the LBA should be reduced under conditions when memories did not undergo reconsolidation but should remain normal when memories underwent reconsolidation (Fig. 7). That was indeed observed. NR2B levels were normal when the memory underwent reconsolidation, but drastically reduced under the conditions in which the memory did not undergo reconsolidation (Fig. 4B). The reduction was subunit-selective, with NR1 subunits constant at all time points. 


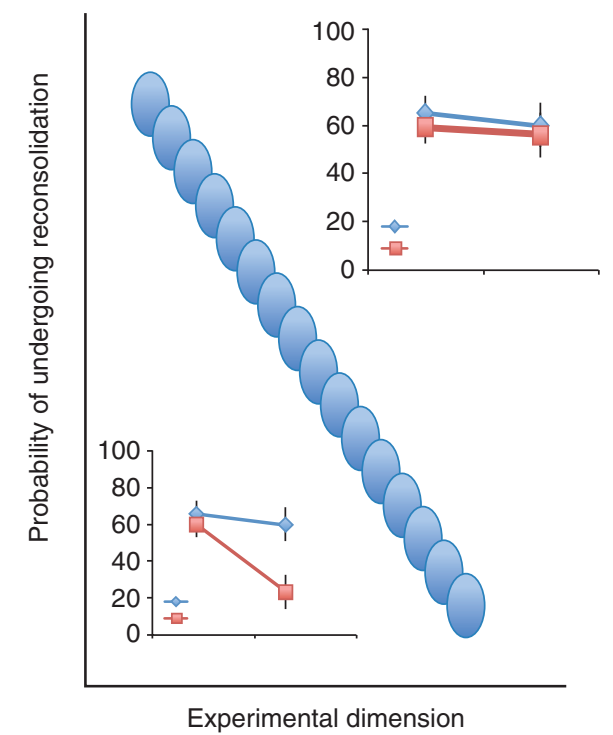

Figure 3. Possible functions describing the constraints on reconsolidation. It is still an open question whether the functions are linear or exponent. Different experimental conditions may produce different functions. The experimental space to the left of the curve is determined by examples in which the memory undergoes reconsolidation as shown in the schematic behavioral impairment. The evidence for constraints on reconsolidation is derived from negative findings as shown in the schematic on the right. That is a logical limitation of the behavioral approach to this issue. Therefore, we suggested that a complementary approach to help resolve this issue would be to identify a molecular correlate for the absence of reconsolidation. This would act as positive evidence for the existence of the constraint.

The suggested role of the NR2B subunits in regulating when fear memory in the LBA will undergo reconsolidation may not generalize to all memory systems or types of memory. Currently, there are several studies that have examined the mechanisms involved in transforming a consolidated memory to a labile state. Although the NR2B subunit is critical for memories to return to a labile state within the LBA for fear conditioning (Ben Mamou et al. 2006), NMDA receptors in the hippocampus and within the amygdala for appetitive memories are thought to play a direct role in the restabili-
Reconsolidation and the Dynamic Nature of Memory

zation process following the reactivation of the memory (Milton et al. 2008; Suzuki et al. 2008). In the hippocampus, voltage-gated calcium channels (VGCCs) (Suzuki et al. 2008) and protein degradation (Lee et al. 2008) are critical for a memory to return to a labile state.

\section{DOES RECONSOLIDATION IMPLY RECAPITULATION OF CONSOLIDATION}

An important but somewhat neglected aspect of this debate is that the protocols used to study reconsolidation are different from those used to study consolidation, which renders comparison of results problematic. For example, in auditory fear conditioning, both CS and US are presented, leading to activation of afferents that relay auditory and pain information to the amygdala. Neurons that are thought to be the site of plasticity in the LBA are proposed to receive concurrent activation by these afferents (Blair et al. 2001). As a consequence, a series of second messenger systems are activated that are thought to lead to transcription and translation of proteins required for consolidation (Maren 2001; Schafe et al. 2001). In reconsolidation studies, however, typically only the CS is presented to reactive and induce plasticity in consolidated memory. Thus, consolidation studies examine the neurobiological changes after a CS and US are presented together, although reconsolidation studies examine neurobiological changes that happen after presentation of a CS alone. For this reason, at the brain systems/circuits and molecular level, consolidation and reconsolidation must be different, as only the former directly activates the pathways that relay US information to the amygdala, which are not directly activated in reconsolidation studies. Therefore, the demonstration of differences in brain regions or circuits mediating consolidation and reconsolidation may be rather trivial (Nader et al. 2005). It remains unclear which of the reported differences between consolidation and reconsolidation reflect genuine differences between the two processes as opposed to differences in the protocols used to induce them. A study in which differences between reconsolidation and consolidation were not attributable to 
K. Nader

A

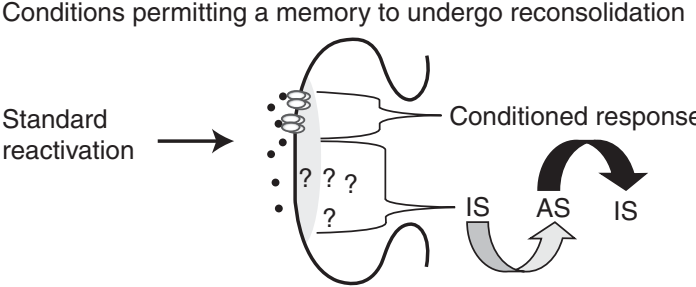

(2) AMPA receptors

Mechanisms that

? transform a consolidated

memory to a labile state

- Glutamate

B Conditions that begin to inhibit reconsolidation from occurring

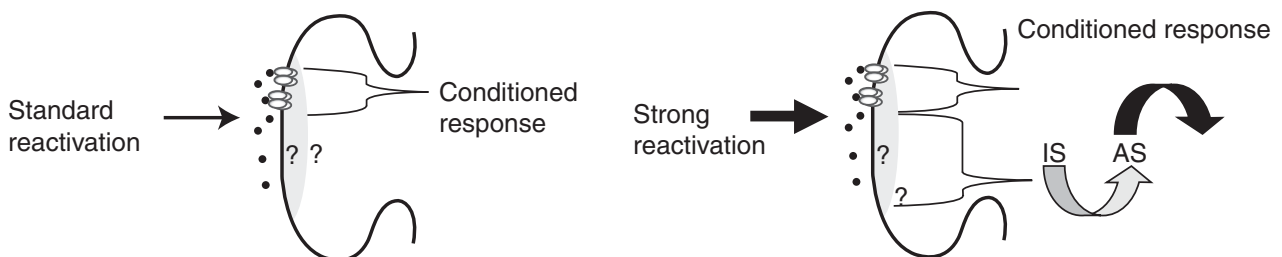

C Conditions that prevent reconsolidation from occurring

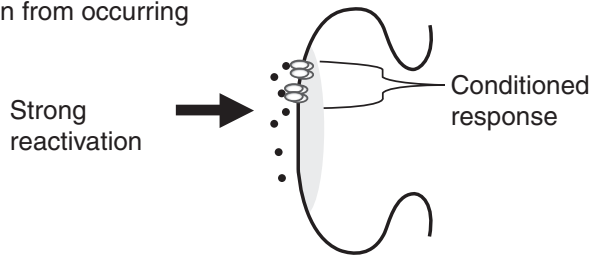

Figure 4. Conceptual diagram showing how boundary conditions could inhibit memories from undergoing reconsolidation across memory types and memory systems. ( $A$ ) Under experimental conditions when a memory undergoes reconsolidation, the mechanisms allowing a memory to be transformed from a consolidated to a labile active state (AS), must be present and functional at the synapse ("?" in the figure). These mechanisms, of course, will involve more than surface receptors and will likely include a number of molecular processes that have yet to be identified. $(B)$ Experimental conditions that begin to inhibit memories from undergoing reconsolidation may lead to a partial reduction in a mechanism that is critical for the induction of reconsolidation. The partial reduction might be sufficient to prevent the induction of reconsolidation when a standard protocol is used. However, there may still be sufficient amounts of this mechanism to permit the memory to undergo reconsolidation when a stronger reactivation is used. $(C)$ Under conditions in which the memory does not undergo reconsolidation, a boundary condition, a necessary mechanism for the induction of reconsolidation, is reduced to the point that alternative reactivation protocols cannot induce the memory to undergo reconsolidation. AMPA, $\alpha$-amino-3-hydroxy-5-methyl-4-isoxazolepropionic; IS, inactive state.

differences in the protocols is the first to shed some light on this issue (Lee et al. 2004). These investigators reported a double dissociation, separating the mechanisms mediating consolidation from those that mediate reconsolidation (Lee et al. 2004; see also von Hertzen and Giese 2005).

\section{POTENTIAL CLINICAL IMPLICATIONS}

The finding that consolidated memories return to a labile state and have to be restored has significant potential implications for a number of clinical conditions, such as PTSD, addiction, obsessive-compulsive disorder (OCD), or delusions/hallucinations. An understanding of the mechanisms mediating reconsolidation could provide the basis for developing new or refining old therapeutic tools to successfully manage some of these conditions. As an example of how this could be applied, imagine a patient with PTSD whose symptoms were resistant to therapy. A new way of treating this condition could be to reactivate the patient's traumatic memory and block its reconsolidation. Theoretically, this may lead to a rapid "cure." 

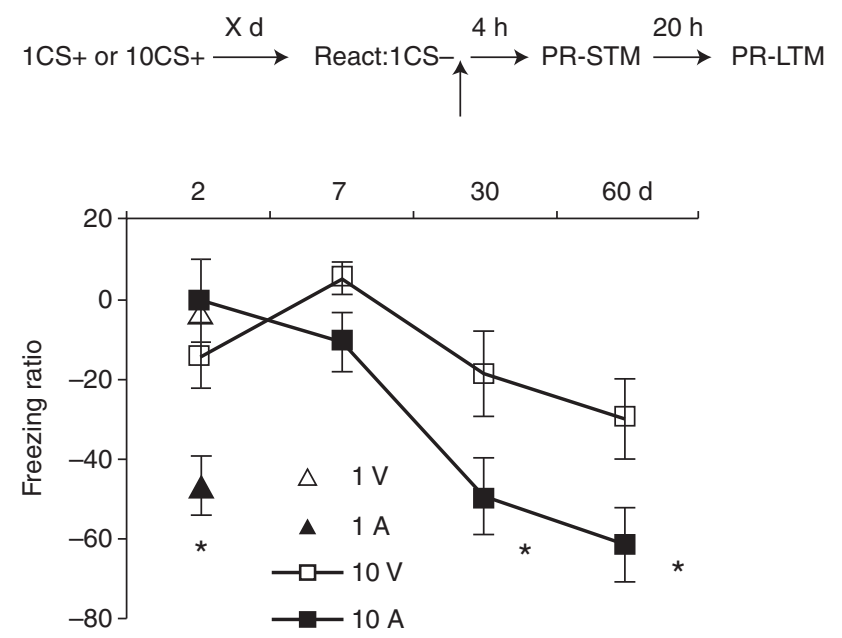

Figure 5. Strong memories undergo reconsolidation at 30 and 60, but not $7 \mathrm{~d}$ after training. The top panel of each subfigure represents the behavior protocol. Separate groups of animals were lateral and basal amygdala (LBA)cannulated and trained with 10-tone foot-shock pairings. The memory was reactivated at 7, 30, or $60 \mathrm{~d}$ after training. The freezing ration was computed as postreactivation long-term memory (PR-LTM) — PR short-term memory $(\mathrm{STM}) /(\mathrm{PR}-\mathrm{STM}) \mathrm{X}^{*} 100 \%$. Intra-LBA anisomycin infusion impaired the PR-LTM only when the strong memory was reactivated at 30 - and $60-\mathrm{d}$ after training. The asterisks $\left(^{*}\right)$ indicate significant group differences. (From Wang et al. 2009; reproduced, with permission, from the authors.)

Early evidence suggests that this may work. Rubin et al. (1969) and Rubin (1976) treated patients suffering from either hallucinations, delusions, major depression, or OCD with electroconvulsive therapy (ECT). In contrast to other studies that administered ECT when the subjects were anaesthetized, Rubin and colleagues kept the patients awake and directed them to focus on the objects of their compulsions or hallucinations. This experimental procedure was thought to reactivate the neural mechanisms mediating those memories when the ECT was delivered. All of the subjects were reportedly "cured" of their condition, even though some had had up to 30 previous ECT treatments while under anesthesia. The majority remained symptom-free for the 2-yr period between the treatment and the publication of the manuscript. The fact that ECT was effective only when the memories were presumed to be reactivated, but not when the memory reactivation was omitted (i.e., when the patient was anesthetized), suggests, in principle, that reconsolidation occurs in humans. Furthermore, this study provides evidence that the possibility of curing someone by removing a memory in a single session may not be so remote.

More recent candidate treatments tend to be less intrusive than ECT (Kroes et al. 2014). For example, $\beta$-adrenergic antagonists, such as propranolol, have few side effects and were reported to block reconsolidation of aversive and appetitive memories preferentially stored in the amygdala. However, behaviorally updating or extinguishing the reactivated memory during the time window of reconsolidation in the absence of drug treatment, or the use of sensory distractors, may also be used to block reconsolidation in potential treatment protocols in humans (Schiller et al. 2010; Schiller and Phelps 2011; Gray and Liotta 2012).

The first attempt to target reconsolidation with a $\beta$-blocker in patients with enduring PTSD symptoms reported a reduction in the strength of traumatic memories after a 15-min intervention (Brunet et al. 2008). It is important to note that some of these patients had been suffering from these PTSD symptoms for close to $30 \mathrm{yr}$. Furthermore, it is remarkable that a single reactivation seems to cause an old and 


\section{K. Nader}
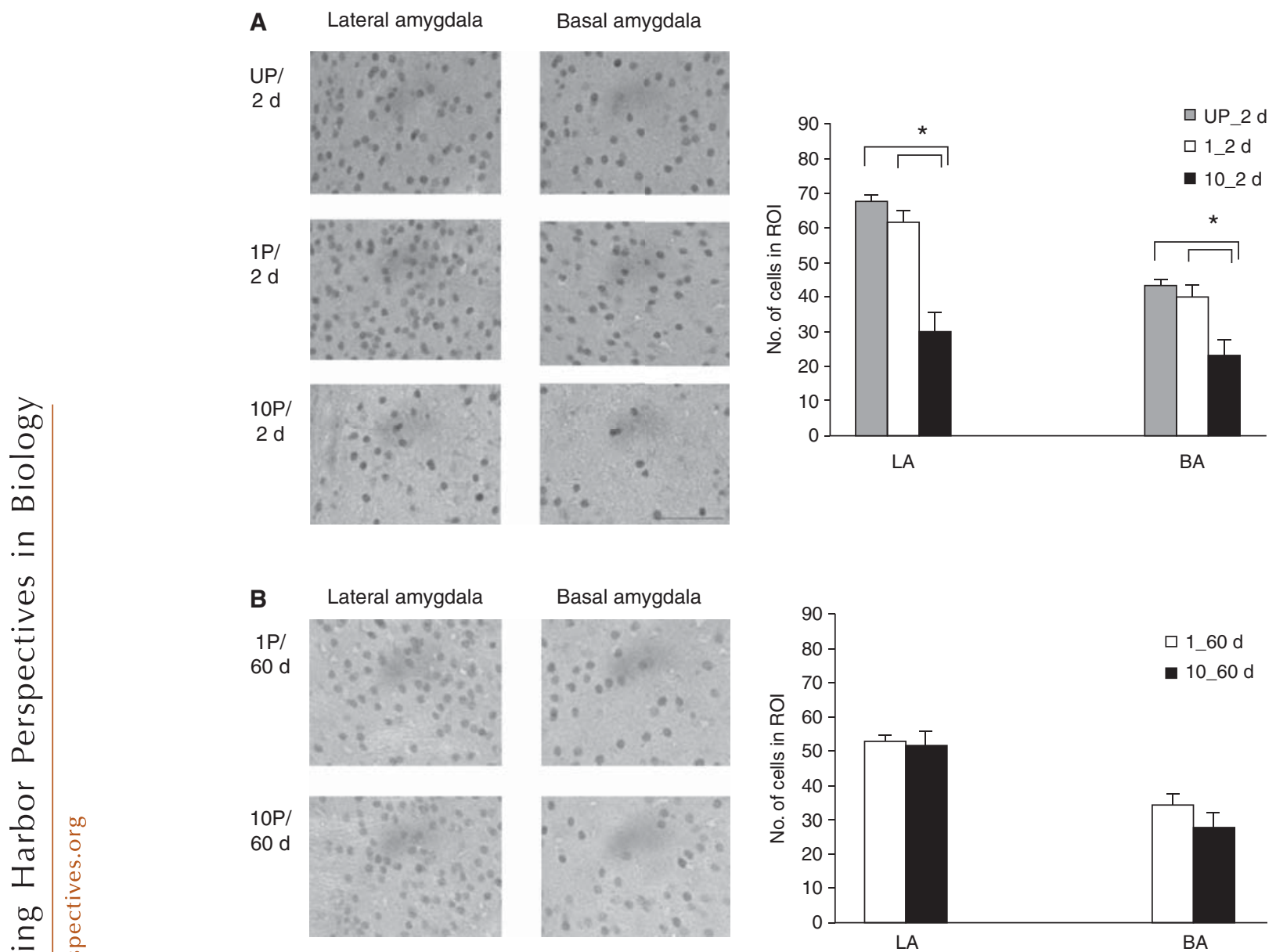

ㅁ1_60 d

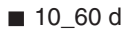

$10 \mathrm{P} /$
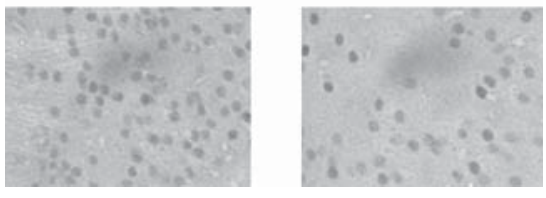

Figure 6. NR2B-subunit levels, assessed by immunohistochemistry (IHC), are inversely related to the ability of the strong memories to undergo reconsolidation over time. (A) Animals received 10-tone foot-shock pairings (10P), one pairing (1P), or one foot shock followed by an unpaired tone (UP). They were killed $2 \mathrm{~d}$ after training, a time when the memory does not undergo reconsolidation, and their brains were later processed for IHC. The left panel represents the actual staining in regions of interest (ROI) in lateral and basal amygdala (LBA) in individual groups $(n=4$ /group). The graph shows the quantification of NR2Bpositive cell numbers in each ROI. Although $1 \mathrm{P}$ and UP animals showed similar level of NR2B-immunostained cells, 10P animals showed significantly less stained cells in either lateral amygdala (LA) or basal amygdala (BA). The asterisks $\left({ }^{*}\right)$ indicate significant group differences. $(B)$ Animals received either 10P or 1P. They were killed $60 \mathrm{~d}$ after training, a time when the memory does undergo reconsolidation, and their brains were later processed for IHC. Both groups show similar level of NR2B-positive cells in LA and BA. All pictures in the left panel are in the same scale. Each data point is represented as mean \pm S.E.M. Scale bar, $80 \mu \mathrm{m}$.

consolidated memory to become labile again. Drug craving (Xue et al. 2012; Saladin et al. 2013) and PTSD (Brunet et al. 2008; Menzies 2012) are two clinical conditions, in which it has been reported that targeting their underlying maintaining mechanisms through reconsolida- tion can lead to some clinical improvement (Nader et al. 2013). However, the results of other studies indicate that the practical usefulness of blocking reconsolidation in the treatment of trauma requires further exploration (Spring et al. 2015; Wood et al. 2015). 
A One pairing memory

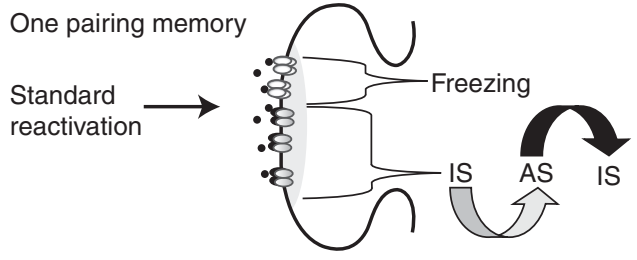

CD AMPA receptors

NR2B subunits

NR1 subunits

- Glutamate

B Ten pairing memory boundary conditions
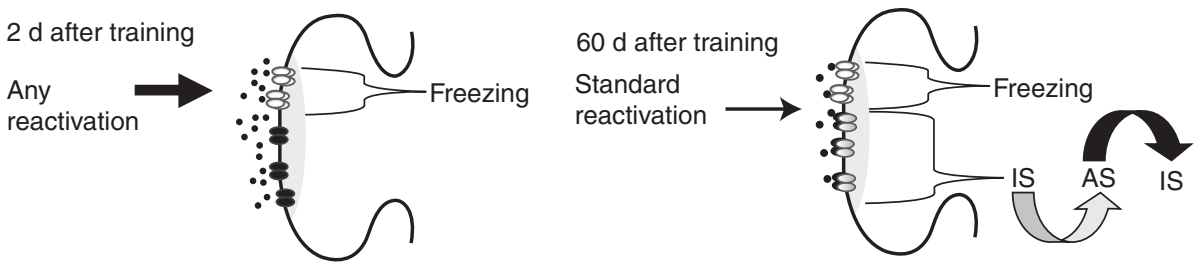

Figure 7. A diagram hypothesizing how strength of auditory fear memory can influence a mechanism that allows reconsolidation to occur at the lateral and basal amygdala (LBA) synapses. (A) After one pairing, NR2B containing $N$-methyl-D-aspartate (NMDA) receptors are activated for the memory to go from a consolidated inactive state (IS) to a labile active state (AS) (gray curved arrow). The labile memory then undergoes reconsolidation and return to IS (black curved arrow). Independently of this mechanism, $\alpha$-amino-3-hydroxy-5-methyl4-isoxazolepropionic (AMPA) receptors are critical for the expression of freezing behavior. After one pairing, there are sufficient NR2B subunits at the synapse for the memory to undergo reconsolidation when standard reactivation procedures are used. (B) After 10 pairings, via hippocampus-mediated mechanisms (not shown), levels of the NR2B, but not NR1, are reduced $2 \mathrm{~d}$ after training. NR2B reduction eliminates a necessary mechanism for the memory to undergo reconsolidation. Hence, reactivation by standard or alternative protocols should be unable to induce reconsolidation. Meanwhile, the existing AMPA receptors will mediate normal expression of freezing. NR2B level returns to normal $60 \mathrm{~d}$ after training. Thus, standard reactivation procedures are now sufficient to induce reconsolidation.

\section{CONCLUSION}

Reconsolidation indicates that the maintenance of memory over time is active rather than passive. The evidence for reconsolidation comes from a spectrum of species, amnesic agents, and reinforcers, spanning all levels of analysis from the molecular and physiological to the behavioral levels, thereby suggesting that that it is a fundamental property of memory.

Reconsolidation remains a topic of intensive research. One area of investigation that is being studied involves the identification of boundary conditions in reconsolidation. I have suggested that identifying a molecular or cellular indicator when memories undergo reconsolidation is a complementary approach that can alleviate some of the problems inherent in attempts to identify boundary conditions on reconsolidation.
There is a growing interest in utilizing reconsolidation blockage as a potential therapeutic tool in several clinical conditions, most importantly PTSD. The use of reconsolidation protocols for clinical purposes must, however, await further exploration.

\section{ACKNOWLEDGMENTS}

K.N. is supported by the Canadian Institutes of Health Research, Natural Sciences and Engineering Research Council of Canada, Canadian Foundation for Innovation, The Volkswagen, Alfred P. Sloan, and EJLB (Echo Foundation). K.N. is the James McGill Chair.

\section{REFERENCES}

Anokhin KV, Tiunova AA, Rose SP. 2002. Reminder effects-Reconsolidation or retrieval deficit? Pharmacological dissection with protein synthesis inhibitors fol- 
lowing reminder for a passive-avoidance task in young chicks. Eur J Neurosci 15: 1759-1765.

Bailey CH, Kandel ER. 1993. Structural changes accompanying memory storage. Annu Rev Physiol 55: 397-426.

Ben Mamou C, Gamache K, Nader K. 2006. NMDA receptors are critical for unleashing consolidated auditory fear memories. Nat Neurosci 9: 1237-1239.

Blair HT, Schafe GE, Bauer EP, Rodrigues SM, LeDoux JE. 2001. Synaptic plasticity in the lateral amygdala: A cellular hypothesis of fear conditioning. Learn Mem 8: 229_ 242.

Bliss TV, Collingridge GL. 1993. A synaptic model of memory: Long-term potentiation in the hippocampus. Nature 361: 31-39.

Bozon B, Davis S, Laroche S. 2003. A requirement for the immediate early gene zif268 in reconsolidation of recognition memory after retrieval. Neuron 40: 695-701.

Brunet A, Orr SP, Tremblay J, Robertson K, Nader K, Pitman RK. 2008. Effect of post-retrieval propranolol on psychophysiologic responding during subsequent script-driven traumatic imagery in post-traumatic stress disorder. $J$ Psychiatry Res 42: 503-506.

Cai D, Pearce K, Chen S, Glanzman DL. 2012. Reconsolidation of long-term memory in Aplysia. Curr Biol 22: $1783-1788$.

Child FM, Epstein HT, Kuzirian AM, Alkon DL. 2003. Memory reconsolidation in hermissenda. Biol Bull 205: 218 219.

Debiec J, Ledoux JE. 2004. Disruption of reconsolidation but not consolidation of auditory fear conditioning by noradrenergic blockade in the amygdala. Neuroscience 129: $267-272$.

Debiec J, LeDoux JE, Nader K. 2002. Cellular and systems reconsolidation in the hippocampus. Neuron 36: $527-$ 538.

De Vietti T, Holiday JH. 1972. Retrograde amnesia produced by electroconvulsive shock after reactivation of a consolidated memory trace: A replication. Psychon Sci 29: 137138.

Doyere V, Debiec J, Monfils MH, Schafe GE, LeDoux JE. 2007. Synapse-specific reconsolidation of distinct fear memories in the lateral amygdala. Nat Neurosci 10: $414-416$.

Dreyfuss JL, Regatieri CV, Jarrouge TR, Cavalheiro RP, Sampaio LO, Nader HB. 2009. Heparan sulfate proteoglycans: Structure, protein interactions and cell signaling. An Acad Bras Cienc 81: 409-429.

Dudai Y. 2004. The neurobiology of consolidations, or, how stable is the engram? Annu Rev Psychol 55: 51-86.

Duncan CP. 1949. The retroactive effect of electroconvulsive shock. J Comp Physiol Psychol 42: 32-44.

Duvarci S, Nader K, Ledoux JE. 2005. Activation of extracellular signal-regulated kinase-mitogen-activated protein kinase cascade in the amygdala is required for memory reconsolidation of auditory fear conditioning. Eur $J$ Neurosci 21: 283-289.

Duvarci S, Mamou CB, Nader K. 2006. Extinction is not a sufficient condition to prevent fear memories from undergoing reconsolidation in the basolateral amygdala. Eur J Neurosci 24: 249-260.
Ebbinghaus M. 1885. Über das Gedächtnis (ed. K. Buehler). Leipzig, Germany.

Eisenberg M, Dudai Y. 2004. Reconsolidation of fresh, remote, and extinguished fear memory in medaka: Old fears don't die. Eur J Neurosci 20: 3397-3403

Eisenberg M, Kobilo T, Berman DE, Dudai Y. 2003. Stability of retrieved memory: Inverse correlation with trace dominance. Science 301: 1102-1104.

Finnie PS, Nader K. 2012. The role of metaplasticity mechanisms in regulating memory destabilization and reconsolidation. Neurosci Biobehav Rev 36: 1667-1707.

Flexner LB, Flexner JB, Stellar E. 1965. Memory and cerebral protein synthesis in mice as affected by graded amounts of puromycin. Exp Neurol 13: 264-272.

Fonseca R, Nagerl UV, Bonhoeffer T. 2006. Neuronal activity determines the protein synthesis dependence of longterm potentiation. Nat Neurosci 9: 478-480.

Glickman S. 1961. Perseverative neural processes and consolidation of the memory trace. Psychol Bull 58: 218-233.

Goelet P, Castellucci VF, Schacher S, Kandel ER. 1986. The long and short of long-term memory-A molecular framework. Nature 322: 419-422.

Gordon WC. 1977a. Similarities of recently acquired and reactivated memories in interference. Am J Psychol 90: 231-242.

Gordon WC. 1977b. Susceptibility of a reactivated memory to the effects of strychnine: A time-dependent phenomenon. Physiol Behav 18: 95-99.

Gordon WC, Spear NE. 1973. Effect of reactivation of a previously acquired memory on the interaction between memories in the rat. J Exp Psychol 99: 349-355.

Gray RM, Liotta RF. 2012. PTSD: Extinction, reconsolidation, and the visual-kinesthetic dissociation protocol. Traumatology 18: 3-16.

Gruest N, Richer P, Hars B. 2004. Memory consolidation and reconsolidation in the rat pup require protein synthesis. J Neurosci 24: 10488-10492.

Hernandez PJ, Kelley AE. 2004. Long-term memory for instrumental responses does not undergo protein synthesis-dependent reconsolidation upon retrieval. Learn Mem 11: 748-754.

Hong I, Kim J, Lee S, Ko HG, Nader K, Kaang BK, Tsien RW, Choi S. 2013. AMPA receptor exchange underlies transient memory destabilization on retrieval. Proc Natl Acad Sci 110: 8218-8223.

Horne CA, Rodriguez WA, Wright TP, Padilla JL. 1997. Time-dependent effects of fructose on the modulation of a reactivated memory. Prog Neuropsychopharmacol Biol Psychiatry 21: 649-658.

Hupbach A, Gomez R, Hardt O, Nadel L. 2007. Reconsolidation of episodic memories: A subtle reminder triggers integration of new information. Learn Mem 14: 47-53.

Kandel ER. 2001. The molecular biology of memory storage: A dialogue between genes and synapses. Science 294: 1030-1038.

Kandel ER, Dudai Y, Mayford MR. 2014. The molecular and systems biology of memory. Cell 157: 163-186.

Kelly A, Laroche S, Davis S. 2003. Activation of mitogenactivated protein kinase/extracellular signal-regulated kinase in hippocampal circuitry is required for consoli- 
dation and reconsolidation of recognition memory. $J$ Neurosci 23: 5354-5360.

Kida S, Josselyn SA, de Ortiz SP, Kogan JH, Chevere I, Masushige S, Silva AJ. 2002. CREB required for the stability of new and reactivated fear memories. Nat Neurosci 5: $348-355$.

Kindt M, Soeter M, Vervliet B. 2009. Beyond extinction: Erasing human fear responses and preventing the return of fear. Nat Neurosci 12: 256-258.

Kroes MC, Tendolkar I, van Wingen GA, van Waarde JA, Strange BA, Fernandez G. 2014. An electroconvulsive therapy procedure impairs reconsolidation of episodic memories in humans. Nat Neurosci 17: 204-206.

Lee JL. 2008. Memory reconsolidation mediates the strengthening of memories by additional learning. Nat Neurosci 11: 1264-1266.

Lee JL. 2009. Reconsolidation: Maintaining memory relevance. Trends Neurosci 32: 413-420.

Lee JL, Everitt BJ, Thomas KL. 2004. Independent cellular processes for hippocampal memory consolidation and reconsolidation. Science 304: 839-843.

Lee JL, Di Ciano P, Thomas KL, Everitt BJ. 2005. Disrupting reconsolidation of drug memories reduces cocaine-seeking behavior. Neuron 47: 795-801.

Lee SH, Choi JH, Lee N, Lee HR, Kim JI, Yu NK, Choi SL, Lee SH, Kim H, Kaang BK. 2008. Synaptic protein degradation underlies destabilization of retrieved fear memory. Science 319: 1253-1256.

Lee SH, Kwak C, Shim J, Kim JE, Choi SL, Kim HF, Jang DJ, Lee JA, Lee K, Lee CH, et al. 2012. A cellular model of memory reconsolidation involves reactivation-induced destabilization and restabilization at the sensorimotor synapse in Aplysia. Proc Natl Acad Sci 109: 14200-14205.

Lewis DJ. 1979. Psychobiology of active and inactive memory. Psychol Bull 86: 1054-1083.

Li Y, Meloni EG, Carlezon WA Jr, Milad MR, Pitman RK, Nader K, Bolshakov VY. 2013. Learning and reconsolidation implicate different synaptic mechanisms. Proc Natl Acad Sci 110: 4798-4803.

Malenka RC, Nicoll RA. 1999. Long-term potentiation-A decade of progress? Science 285: 1870-1874.

Maren S. 2001. Neurobiology of Pavlovian fear conditioning. Annu Rev Neurosci 24: 897-931.

Martin SJ, Grimwood PD, Morris RG. 2000. Synaptic plasticity and memory: An evaluation of the hypothesis. Anпu Rev Neurosci 23: 649-711.

McGaugh JL. 1966. Time-dependent processes in memory storage. Science 153: 1351-1358.

McGaugh JL. 2004. The amygdala modulates the consolidation of memories of emotionally arousing experiences. Annu Rev Neurosci 27: 1-28.

McGaugh JL, Krivanek JA. 1970. Strychnine effects on discrimination learning in mice: Effects of dose and time of administration. Physiol Behav 5: 1437-1442.

Menzies RP. 2012. Propranolol, traumatic memories, and amnesia: A study of 36 cases. J Clin Psychiatry 73: 129_ 130.

Milekic MH, Alberini CM. 2002. Temporally graded requirement for protein synthesis following memory reactivation. Neuron 36: 521-525.
Miller CA, Marshall JF. 2005. Molecular substrates for retrieval and reconsolidation of cocaine-associated contextual memory. Neuron 47: 873-884.

Miller RR, Springer AD. 1973. Amnesia, consolidation, and retrieval. Psychol Rev 80: 69-79.

Milton AL, Lee JL, Butler VJ, Gardner R, Everitt BJ. 2008. Intra-amygdala and systemic antagonism of NMDA receptors prevents the reconsolidation of drug-associated memory and impairs subsequently both novel and previously acquired drug-seeking behaviors. J Neurosci 28: 8230-8237.

Misanin JR, Miller RR, Lewis DJ. 1968. Retrograde amnesia produced by electroconvulsive shock after reactivation of a consolidated memory trace. Science 160: 203-204.

Morris RG, Inglis J, Ainge JA, Olverman HJ, Tulloch J, Dudai Y, Kelly PA. 2006. Memory reconsolidation: Sensitivity of spatial memory to inhibition of protein synthesis in dorsal hippocampus during encoding and retrieval. Neuron 50: $479-489$.

Müller GE, Pilzecker A. 1900. Experimentelle beitrage zur lehre vom gedachtnis. $Z$ Psychol 1: 1-30.

Nader K, Hardt O. 2009. A single standard for memory: The case for reconsolidation. Nat Rev Neurosci 10: 224-234.

Nader K, Schafe GE, Le Doux JE. 2000. Fear memories require protein synthesis in the amygdala for reconsolidation after retrieval. Nature 406: 722-726.

Nader K, Hardt O, Wang SH. 2005. Response to Alberini: Right answer, wrong question. Trends Neurosci 28: $346-$ 347.

Nader K, Hardt O, Lanius R. 2013. Memory as a new therapeutic target. Dialogues Clin Neurosci 15: 475-486.

Pedreira ME, Maldonado H. 2003. Protein synthesis subserves reconsolidation or extinction depending on reminder duration. Neuron 38: 863-869.

Pedreira ME, Perez-Cuesta LM, Maldonado H. 2002. Reactivation and reconsolidation of long-term memory in the crab Chasmagnathus: Protein synthesis requirement and mediation by NMDA-type glutamatergic receptors. $J$ Neurosci 22: 8305-8311.

Pedreira ME, Perez-Cuesta LM, Maldonado H. 2004. Mismatch between what is expected and what actually occurs triggers memory reconsolidation or extinction. Learn Mem 11: 579-585.

Przybyslawski J, Sara SJ. 1997. Reconsolidation of memory after its reactivation. Behav Brain Res 84: 241-246.

Przybyslawski J, Roullet P, Sara SJ. 1999. Attenuation of emotional and nonemotional memories after their reactivation: Role of $\beta$ adrenergic receptors. J Neurosci 19: 6623-6628.

Rodrigues SM, LeDoux JE, Sapolsky RM. 2009. The influence of stress hormones on fear circuitry. Annu Rev Neurosci 32: 289-313.

Rodriguez WA, Rodriguez SB, Phillips MY, Martinez JL Jr. 1993. Post-reactivation cocaine administration facilitates later acquisition of an avoidance response in rats. Behav Brain Res 59: 125-129.

Rodriguez WA, Horne CA, Padilla JL. 1999. Effects of glucose and fructose on recently reactivated and recently acquired memories. Prog Neuropsychopharmacol Biol Psychiatry 23: 1285-1317. 
K. Nader

Rose JK, Rankin CH. 2006. Blocking memory reconsolidation reverses memory-associated changes in glutamate receptor expression. J Neurosci 26: $11582-11587$.

Rubin RD. 1976. Clinical use of retrograde amnesia produced by electroconvulsive shock: A conditioning hypothesis. Can Psychiatry Assoc J 21: 87-90.

Rubin RD, Fried R, Franks CM. 1969. New application of ECT. In Advances in behavior therapy (ed. Rubin RD, Franks C), pp. 37-44. Academic, New York.

Rumpel S, LeDoux J, Zador A, Malinow R. 2005. Postsynaptic receptor trafficking underlying a form of associative learning. Science 308: 83-88.

Saladin ME, Gray KM, McRae-Clark AL, Larowe SD, Yeatts SD, Baker NL, Hartwell KJ, Brady KT. 2013. A double blind, placebo-controlled study of the effects of post-retrieval propranolol on reconsolidation of memory for craving and cue reactivity in cocaine dependent humans. Psychopharmacology (Berl) 226: 721-737.

Sangha S, Scheibenstock A, Lukowiak K. 2003. Reconsolidation of a long-term memory in Lymnaea requires new protein and RNA synthesis and the soma of right pedal dorsal 1. J Neurosci 23: 8034-8040.

Sara S. 2000. Retrieval and reconsolidation: Toward a neurobiology of remembering. Learn Mem 7: 73-84.

Schafe GE, LeDoux JE. 2000. Memory consolidation of auditory Pavlovian fear conditioning requires protein synthesis and protein kinase A in the amygdala. J Neurosci 20: RC96.

Schafe GE, Nader K, Blair HT, LeDoux JE. 2001. Memory consolidation of Pavlovian fear conditioning: A cellular and molecular perspective. Trends Neurosci 24: 540-546.

Schiller D, Phelps EA. 2011. Does reconsolidation occur in humans? Front Behav Neurosci 5: 24.

Schiller D, Monfils MH, Raio CM, Johnson DC, Ledoux JE, Phelps EA. 2010. Preventing the return of fear in humans using reconsolidation update mechanisms. Nature 463: 49-53.

Spear N. 1973. Retrieval of memory in animals. Psychol Rev 80: 163-194.

Spring JD, Wood NE, Mueller-Pfeifer C, Milad MR, Pitman RK, Orr SP. 2015. Prereactivation propranolol fails to reduce skin conductance reactivity to prepared fear-conditioned stimuli. Psychophysiology 52: 407-415.

Stollhoff N, Menzel R, Eisenhardt D. 2005. Spontaneous recovery from extinction depends on the reconsolidation of the acquisition memory in an appetitive learning paradigm in the honeybee (Apis mellifera). J Neurosci 25: 4485-4492.
Suzuki A, Josselyn SA, Frankland PW, Masushige S, Silva AJ, Kida S. 2004. Memory reconsolidation and extinction have distinct temporal and biochemical signatures. J Neurosci 24: 4787-4795.

Suzuki A, Mukawa T, Tsukagoshi A, Frankland PW, Kida S. 2008. Activation of LVGCCs and CB1 receptors required for destabilization of reactivated contextual fear memories. Learn Mem 15: 426-433.

Taubenfeld SM, Milekic MH, Monti B, Alberini CM. 2001. The consolidation of new but not reactivated memory requires hippocampal C/EBP $\beta$. Nat Neurosci 4: 813818.

Tronson NC, Wiseman SL, Olausson P, Taylor JR. 2006. Bidirectional behavioral plasticity of memory reconsolidation depends on amygdalar protein kinase A. Nat Neurosci 9: 167-169.

Tsvetkov E, Carlezon WA, Benes FM, Kandel ER, Bolshakov VY. 2002. Fear conditioning occludes LTP-induced presynaptic enhancement of synaptic transmission in the cortical pathway to the lateral amygdala. Neuron 34: 289-300.

Valjent E, Aubier B, Corbille AG, Brami-Cherrier K, Caboche J, Topilko P, Girault JA, Herve D. 2006. Plasticity-associated gene Krox24/Zif268 is required for longlasting behavioral effects of cocaine. J Neurosci 26: 4956-4960.

von Hertzen LS, Giese KP. 2005. Memory reconsolidation engages only a subset of immediate-early genes induced during consolidation. J Neurosci 25: $1935-$ 1942.

Walker MP, Brakefield T, Hobson JA, Stickgold R. 2003. Dissociable stages of human memory consolidation and reconsolidation. Nature 425: 616-620.

Wang SH, Ostlund SB, Nader K, Balleine BW. 2005. Consolidation and reconsolidation of incentive learning in the amygdala. J Neurosci 25: 830-835.

Wang SH, de Oliveira Alvares L, Nader K. 2009. Cellular and systems mechanisms of memory strength as a constraint on auditory fear reconsolidation. Nat Neurosci 12: 905912.

Wood NE, Rosasco ML, Suris AM, Spring JD, Marin MF, Lasko NB, Goetz JM, Fischer AM, Orr SP, Pitman RK. 2015. Pharmacological blockade of memory reconsolidation in posttraumatic stress disorder: Three negative psychophysiological studies. Psychiatry Res 225: 31-39.

Xue YX, Luo YX, Wu P, Shi HS, Xue LF, Chen C, Zhu WL, Ding ZB, Bao YP, Shi J, et al. 2012. A memory retrievalextinction procedure to prevent drug craving and relapse. Science 336: 241-245. 


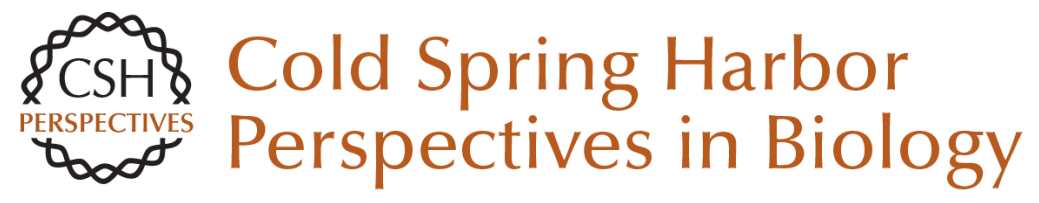

\section{Reconsolidation and the Dynamic Nature of Memory}

Karim Nader

Cold Spring Harb Perspect Biol 2015; doi: 10.1101/cshperspect.a021782 originally published online September 9, 2015

\section{Subject Collection Learning and Memory}

Large-Scale Fluorescence Calcium-Imaging Methods for Studies of Long-Term Memory in Behaving Mammals Pablo Jercog, Thomas Rogerson and Mark J. Schnitzer

Exploring Memory Representations with

Activity-Based Genetics

Mark Mayford and Leon Reijmers

The Origins and Organization of Vertebrate

Pavlovian Conditioning

Michael S. Fanselow and Kate M. Wassum

The Corticohippocampal Circuit, Synaptic

Plasticity, and Memory Jayeeta Basu and Steven A. Siegelbaum

Motor Learning and the Cerebellum Chris I. De Zeeuw and Michiel M. Ten Brinke

The Striatum: Where Skills and Habits Meet Ann M. Graybiel and Scott T. Grafton

Molecular Genetic Strategies in the Study of Corticohippocampal Circuits

Christopher C. Angelakos and Ted Abel

Nonassociative Learning in Invertebrates John H. Byrne and Robert D. Hawkins
The Role of Functional Prion-Like Proteins in the Persistence of Memory

Kausik Si and Eric R. Kandel

Working Memory: Maintenance, Updating, and the

Realization of Intentions

Lars Nyberg and Johan Eriksson

Memory Retrieval in Mice and Men Aya Ben-Yakov, Yadin Dudai and Mark R. Mayford

Reconsolidation and the Dynamic Nature of

Memory

Karim Nader

Memory Consolidation

Larry R. Squire, Lisa Genzel, John T. Wixted, et al.

Structural Components of Synaptic Plasticity and Memory Consolidation

Craig H. Bailey, Eric R. Kandel and Kristen M. Harris

Associative Learning in Invertebrates Robert D. Hawkins and John H. Byrne

The Regulation of Transcription in Memory Consolidation Cristina M. Alberini and Eric R. Kandel

For additional articles in this collection, see http://cshperspectives.cshlp.org/cgi/collection/

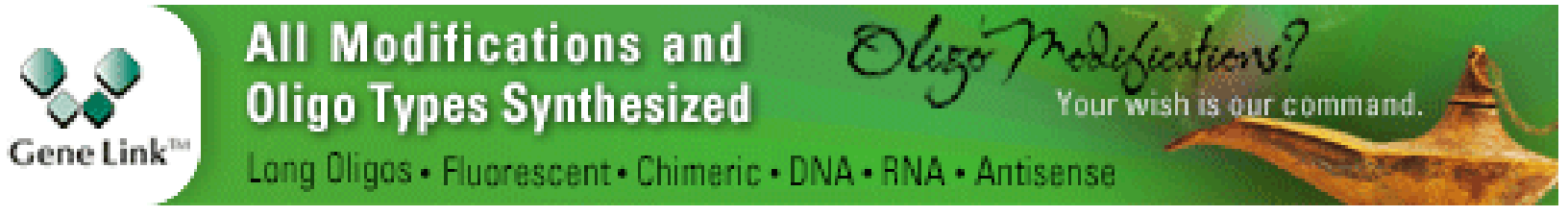

